\title{
Repeated mosquito net distributions, improved treatment, and trends in malaria cases in sentinel health facilities in Papua New Guinea
}

\author{
Daniela Rodriguez-Rodriguez ${ }^{1,2,3}$, Seri Maraga ${ }^{3}$, Lina Lorry ${ }^{3}$, Leanne J. Robinson ${ }^{3,4,5}$, Peter M. Siba ${ }^{3}$, \\ Ivo Mueller ${ }^{4,6}$, Justin Pulford ${ }^{7}$, Amanda Ross ${ }^{1,2}$ and Manuel W. Hetzel ${ }^{1,2^{*}}$ (D)
}

\begin{abstract}
Background: Long-lasting insecticidal nets (LLIN), improved diagnosis and artemisinin-based combination therapy (ACT) have reduced malaria prevalence in Papua New Guinea since 2008. Yet, national incidence trends are inconclusive due to confounding effects of the scale-up of rapid diagnostic tests, and inconsistencies in routine reporting.

Methods: Malaria trends and their association with LLIN and ACT roll-out between 2010 and 2014 in seven sentinel health facilities were analysed. The analysis included 35,329 fever patients. Intervention effects were estimated using regression models.

Results: Malaria incidence initially ranged from 20 to 115/1000 population; subsequent trends varied by site. Overall, LLIN distributions had a cumulative effect, reducing the number of malaria cases with each round (incidence rate ratio ranging from 0.12 to 0.53 in five sites). No significant reduction was associated with ACT introduction. Plasmodium falciparum remained the dominant parasite in all sentinel health facilities. Resurgence occurred in one site in which a shift to early and outdoor biting of anophelines had previously been documented.

Conclusions: LLINs, but not ACT, were associated with reductions of malaria cases in a range of settings, but sustainability of the gains appear to depend on local factors. Malaria programmes covering diverse transmission settings such as Papua New Guinea must consider local heterogeneity when choosing interventions and ensure continuous monitoring of trends.
\end{abstract}

Keywords: Malaria, Incidence, Vector control, Artemisinin-based combination therapy, Plasmodium falciparum, Plasmodium vivax

\section{Background}

Malaria in Papua New Guinea (PNG) was described by Koch in $1900[1,2]$ and to date malaria transmission remains endemic in PNG especially in areas below $1400 \mathrm{~m}$ altitude $[3,4]$. Over the last century, the epidemiology of malaria in PNG has been influenced by control and elimination efforts [2, 4-6]. In the 1950s to 1980 s, PNG had joined efforts of the Global Malaria Eradication Programme with spraying of dichlorodiphenyltrichloroethane (DDT) and mass drug administration

\footnotetext{
*Correspondence: manuel.hetzel@swisstph.ch

${ }^{1}$ Swiss Tropical and Public Health Institute, Basel, Switzerland

Full list of author information is available at the end of the article
}

(primarily chloroquine) [6]. The programme concluded before elimination was achieved and malaria resurged in the 1990s [2, 4]. In 2004, control efforts were re-intensified with funding from the Global Fund to Fight AIDS, Tuberculosis and Malaria to the PNG national malaria control programme (NMCP). Since then, the NMCP has promoted: (1) the country-wide free distribution of longlasting insecticidal nets (LLIN); (2) behaviour change campaigns; and, (3) the scaling-up of parasitological diagnosis by rapid diagnostic test (RDT) or microscopy, together with the introduction of artemisinin-based combination therapy (ACT), specifically artemetherlumefantrine [7]. 
Since this last scale-up, the malaria burden in PNG has steadily decreased as reflected in declining prevalence of infection [8], incidence [9] and transmission [10]. However, malaria control efforts are intrinsically affected by the great environmental and socio-cultural diversity across the country, including a major mountain range over the length of the main island, dense rainforests in the highlands, lowland and coastal areas, and large wetlands surrounding major rivers [2]. This diversity has influenced human population distribution, human behaviour and mosquito ecology. All this, and the presence of four human pathogenic malaria parasites (Plasmodium falciparum, Plasmodium vivax, Plasmodium malariae, Plasmodium ovale), results in a complex malaria epidemiology with heterogeneous levels of endemicity $[2,3,5,11]$.

While changes in malaria prevalence have been consistently investigated since 2008 [8], national trends in malaria incidence are inconclusive and difficult to interpret due to confounding effects of the scale-up of RDTs, changes in health facility reporting forms, and inconsistencies in routine reporting [7].
This study aimed to estimate malaria trends over time (2010-2014) in seven sentinel health facilities (SHF) and assess the effect of repeated household-level distributions of LLINs and the introduction of ACT in distinct epidemiological settings across PNG.

\section{Methods}

\section{Study design}

A health facility based longitudinal study established surveillance of malaria cases, severity of symptoms, net use and parasite species composition in seven purposively selected sentinel health facilities from 2010 to 2014 (Fig. 1). Intervention roll-out was recorded for each site. In four sites, a baseline population census was conducted in the catchment areas of the SHF. In addition, satellite data was extracted for each site and for the duration of the surveillance period to complement clinical data with environmental data.

\section{Study sites}

SHFs were functioning health centres and one sub-centre (Sausi), accessible by road or air, with a catchment population of at least 5000 people, that regularly reported

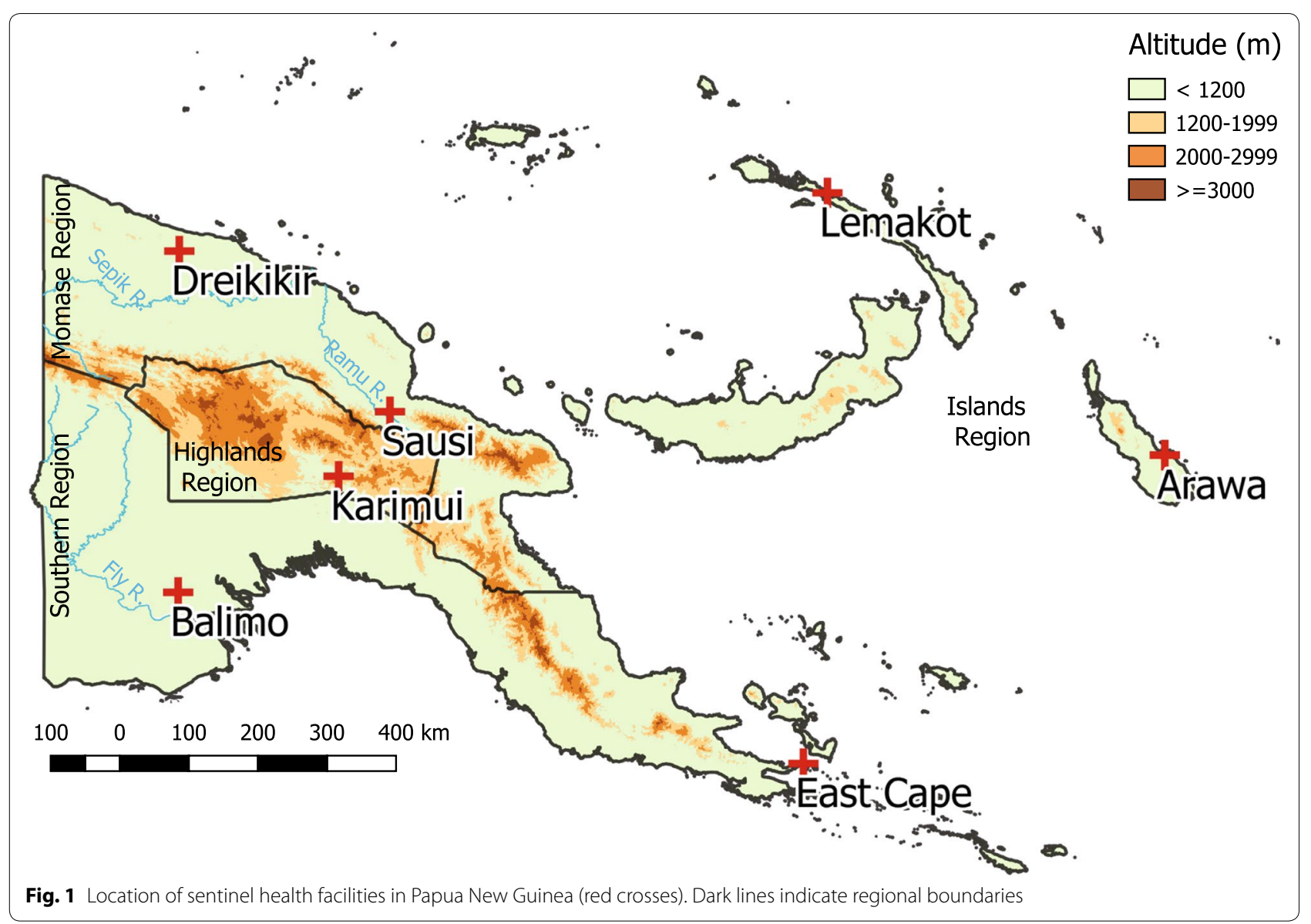


malaria cases. The catchment area defined by the local authorities was adopted for the surveillance. Surveillance activities were established as part of the continuous independent evaluation of the NMCP [4, 7]. Seven SHFs were selected; two each from Southern, Momase and Islands regions, and one from the Highlands region where the malaria burden is lower due to higher altitudes [3]. A description of each site is provided in Additional file 1.

\section{Data collection}

\section{Clinical data at the sentinel health facilities}

The surveillance period in each SHF and the timing of LLIN distribution rounds and introduction of ACT as first-line treatment are provided in Additional file 2.

All outpatient cases attending a SHF were routinely screened for a history of self- reported fever in the previous 3 days ('fever case'). Study-related procedures were performed by registered nursing officers or community health workers ("study nurses") trained in the proper performance of capillary blood sample collection, the use and reading of RDT test kits according to the manufacturer's guidelines, the disposal of bio-hazardous waste, and the recording or results according to the study protocol. The study nurses were based full-time at the facility and collected a capillary blood sample by finger-prick from all consenting fever patients for: (1) point-of-care diagnosis of malaria by RDT; (2) thick and thin blood smear for malaria diagnosis by light microscopy; and, (3) measurement of haemoglobin $(\mathrm{Hb})$ concentration. All RDT-positive cases were considered 'malaria cases' in this analysis. Severe malaria was defined as RDT-positive cases presenting with at least one of the following danger signs: impaired consciousness (including coma or convulsions), difficulty breathing, or severe anaemia $(\mathrm{Hb}<8 \mathrm{~g} /$ $\mathrm{dl}$, or $<7 \mathrm{~g} / \mathrm{dl}$ for children under 5 years old and pregnant women). Demographic details of the patients (age, sex, pregnancy status) and self-reported mosquito net use the previous night were recorded on paper case report forms alongside selected clinical indicators, including axillary temperature, $\mathrm{Hb}$ measurement and RDT results. Patients were then transferred to a health facility clinician for further examination. The final diagnosis as determined by the health facility clinician and prescribed treatment were recorded in the same case report form. The study team ensured availability of RDTs during the surveillance period.

RDTs (ICT Malaria Combo HRP2/aldolase, ICT Diagnostics, South Africa) were used following manufacturer's guidelines. A sub-sample was further examined by light microscopy at the Papua New Guinea Institute of Medical Research (PNGIMR) to identify the Plasmodium species (Additional file 3). Microscopy slides were fixed with methanol (thin smear), stained with Giemsa (thin and thick smear) and read independently by two microscopists. Discordant reads were confirmed with a third read by a senior microscopist (World Health Organization level 1 or 2). The number of parasites was counted for 200 white blood cells and a slide was declared negative after reading a minimum of 200 thick film fields. $\mathrm{Hb}$ concentration was measured using a HemoCue $\mathrm{Hb} 201+$ Analyser (HemoCue AB, Sweden) and axillary temperature with a digital thermometer.

\section{Demographic composition}

A population census was conducted in the catchment areas of East Cape, Karimui, Sausi and Lemakot at the beginning of the surveillance period. The available funding was insufficient to conduct a baseline census in the three remaining SHFs. For the census village leaders assisted in the identification of households and enumeration of household members. The variables captured for each household included: household size, and age and sex of each household member. The annual population growth rate of $3.1 \%$ was obtained from the National Statistics Office [12].

\section{Environmental data}

Rainfall (product 3B43) and Enhanced Vegetation Index (EVI; products MOD13Q1 and MOD13A3) data were extracted from remote-sensing databases by the Tropical Rainfall Measuring Mission (TRMM) and the Earth Observing System (EOS) respectively. Rainfall data were accessed using the Mirador system in the NASA Goddard Earth Sciences Data and Information Services Center (GES DISC) website [13-15]. EVI data were accessed using the NASA Earth Data Search website [16]. In addition the annual occurrence of the El Niño/La Niña phenomena was extracted from the NASA Earth Observatory [17]. Key environmental variables are available in Additional file 4.

\section{Data analysis}

Statistical data analysis was conducted using Stata/IC v.13.1 (Stata Corp LP., College Station, USA). Monthly data were graphically displayed to visualize trends in the numbers of fevers and malaria cases by SHF. Monthly accumulated rainfall in $\mathrm{mm}$ (product 3B43), was included as proxy of site-specific seasonality [13-15]. Missing periods in surveillance data reflect temporary unavailability of study nurses due to leave or staff change and were not related to particular times of the year.

The annual proportions of RDT-positive fever cases (RDT positivity) were calculated with $95 \%$ exact confidence interval (CI). The Plasmodium species composition was estimated from the light microscopy results. Details are provided in Additional file 3. 
For the four sites with available census data, malaria incidence (all cases with a positive RDT) and 'severe malaria' incidence were calculated per 1000 population per year. Population denominators were adjusted for an annual growth rate of $3.1 \%$.

The association between the roll-out of interventions (each of the three rounds of LLIN distribution and of the introduction of ACT as first-line treatment for testconfirmed malaria) and the number of malaria cases was assessed using regression models. The number of cases was used as the outcome since denominators were only available in four sites. To investigate the effect of LLIN distribution rounds, malaria cases were disaggregated by age groups for each LLIN distribution round. Regression models were used to assess the effect of both interventions simultaneously in the seven sites. The LLIN distribution variable had three different values, one for each period between LLIN distributions. The ACT variable was binary, with value zero before the introduction of $\mathrm{ACT}$ and value one thereafter. In preliminary analyses, time since the intervention was included as a variable. However, due to the limited number of observations for each site and the need for simplicity for interpretation these variables were not included in the final model.

Negative binomial regression was used to estimate the effect of the interventions on the monthly aggregate number of malaria cases. Fixed effects were included for the interventions and further covariates. Separate models were applied for each SHF after first establishing that the effects of the LLIN rounds were significantly different between sites using interactions terms. Due to convergence limitations, Poisson regression was used for the model with interactions.

The use of environmental variables such as rainfall (with and without time-lag) and EVI was explored. Initially rainfall was included in the model as a monthly mean per day and alternatively as accumulated monthly aggregate. Introduction of these variables in the model was explored with and without time-lags (1 month and 2 months). EVI variables were similarly explored in the model. The monthly averages of two different EVI products were introduced in the model with and without time-lag. These variables were later omitted from the model due to poor predictive ability. Finally, the estimates were adjusted for El Niño and La Niña annual occurrence. El Niño/La Niña variable was introduced in the model as a categorical variable with 3 possible values for annual occurrence (El Niño in 2010, La Niña in 2011 and 2012 and none in 2013 and 2014).

\section{Results}

During the surveillance period, a total of 35,329 fever cases were recorded across all SHFs. RDT results were available for 98\% (range: 94-99\%) of all cases (Table 1).
Table 1 Number of fever cases and rapid diagnostic test result by sentinel health facility

\begin{tabular}{|c|c|c|c|}
\hline Health facility & $\begin{array}{l}\text { Fever cases } \\
\mathrm{N}\end{array}$ & $\begin{array}{l}\text { RDT positive } \mathrm{N} \\
(\%, 95 \% \mathrm{Cl})\end{array}$ & $\begin{array}{l}\text { RDT not done } \mathrm{N} \\
(\%, 95 \% \mathrm{Cl})\end{array}$ \\
\hline Balimo & 1596 & $\begin{array}{l}57 \\
(4,3-5)\end{array}$ & $\begin{array}{l}100 \\
(6,5-8)\end{array}$ \\
\hline East Cape & 7311 & $\begin{array}{l}3601 \\
(49,48-50)\end{array}$ & $\begin{array}{l}137 \\
(2,1.6-2.2)\end{array}$ \\
\hline Karimui & 3166 & $\begin{array}{l}583 \\
(18,17-20)\end{array}$ & $\begin{array}{l}34 \\
(1,0.7-1.5)\end{array}$ \\
\hline Dreikikir & 3869 & $\begin{array}{l}876 \\
(23,21-24)\end{array}$ & $\begin{array}{l}27 \\
(0.7,0.5-1.0)\end{array}$ \\
\hline Sausi & 6450 & $\begin{array}{l}1654 \\
(26,25-27)\end{array}$ & $\begin{array}{l}238 \\
(4,3-4)\end{array}$ \\
\hline Arawa & 3183 & $\begin{array}{l}439 \\
(14,13-15)\end{array}$ & $\begin{array}{l}61 \\
(2,1-2)\end{array}$ \\
\hline Lemakot & 9754 & $\begin{array}{l}4111 \\
(42,41-43)\end{array}$ & $\begin{array}{l}77 \\
(0.7,0.6-1.0)\end{array}$ \\
\hline Total & 35,329 & $\begin{array}{l}11,321 \\
(32,32-33)\end{array}$ & $\begin{array}{l}674 \\
(2,1.8-2.1)\end{array}$ \\
\hline
\end{tabular}

$R D T$ rapid diagnostic test, $\mathrm{Cl}$ confidence interval

The pooled RDT positivity was $32 \%$. Site-specific RDT positivity ranged from $4 \%$ in Balimo to $49 \%$ in East Cape.

The pattern of fever and malaria cases varied over the surveillance period and between SHFs (Figs. 2, 3, 4 and 5). All sites displayed monthly variations but there was no clear relationship with rainfall patterns. The number of fever and malaria cases decreased over the surveillance period in all sites except in Dreikikir and Sausi, where after an initial decrease an increase was noted in 2014. Malaria cases initially increased in Lemakot (2012), but decreased steadily thereafter. Annual RDT positivity decreased steadily over the surveillance period in most sites but fluctuations were observed especially in sites with low numbers of cases. A substantial increase in RDT positivity in Lemakot (from 35 to $68 \%$ ) in the year 2012 with proportional increase in $P$. vivax and a spike of cases in women aged 15-20 (Additional file 6) suggests a local epidemic.

Plasmodium falciparum was the predominant species in all sites and all years even though species composition fluctuated over time and differed between sites. Balimo was the only SHF in which no infections with $P$. vivax were detected. Proportional increases of $P$. vivax were observed in Lemakot (2012) and Sausi (2014) at a time when the total number of malaria cases also increased (Figs. 2 and 5). Over the entire surveillance period, only $0.2 \%$ of malaria cases were diagnosed with $P$. malariae and $0.02 \%$ with $P$. ovale.

The annual incidence rate of malaria calculated for four sites ranged from 1/1000 population in Karimui in 2014 

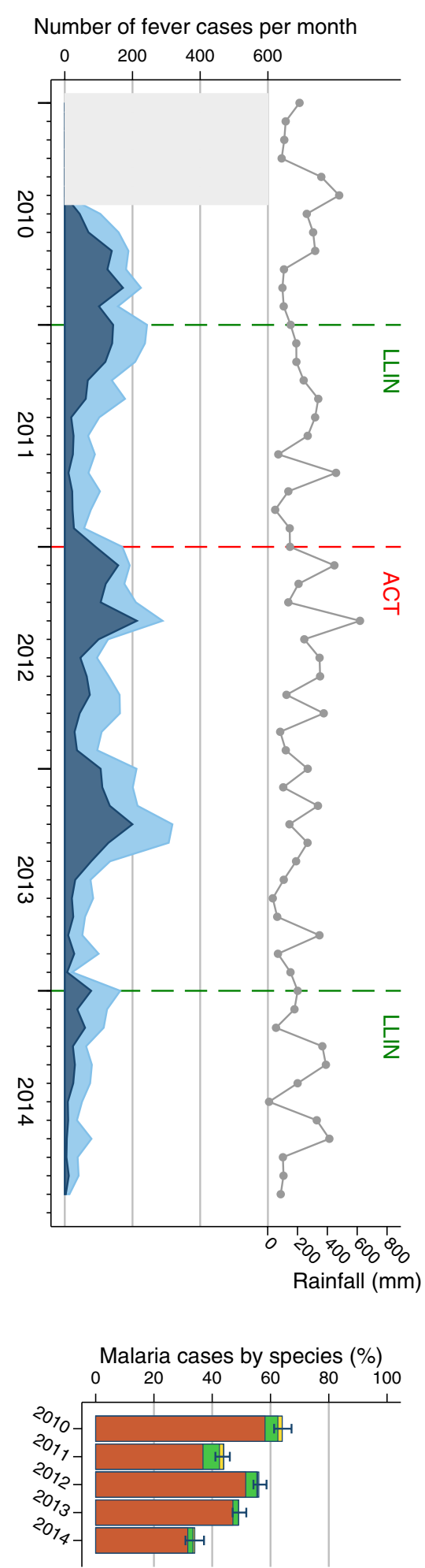
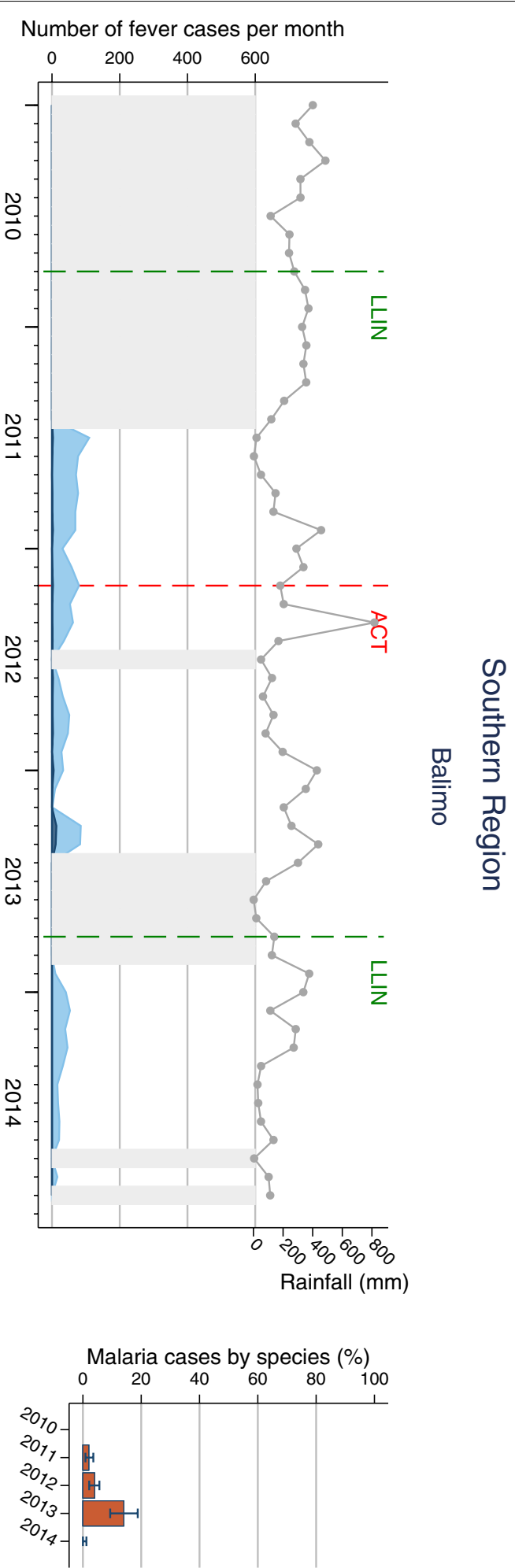

Fig. 2 Malaria cases in Southern Region (Balimo and East Cape) sites. Left of each panel: monthly number of fever cases RDT negative (bright blue) and RDT positive (dark blue); cumulative monthly rainfall (grey line); timing of LLIN distribution and introduction of ACT (vertical dashed lines). Missing data is indicated by light grey shaded background. Right of each panel: annual RDT positivity (bar total) by species: P. falciparum (orange), P. vivax (green), mixed infections (yellow), no species data available (white) 


\section{Number of fever cases per month}

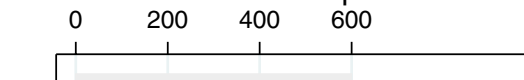

N

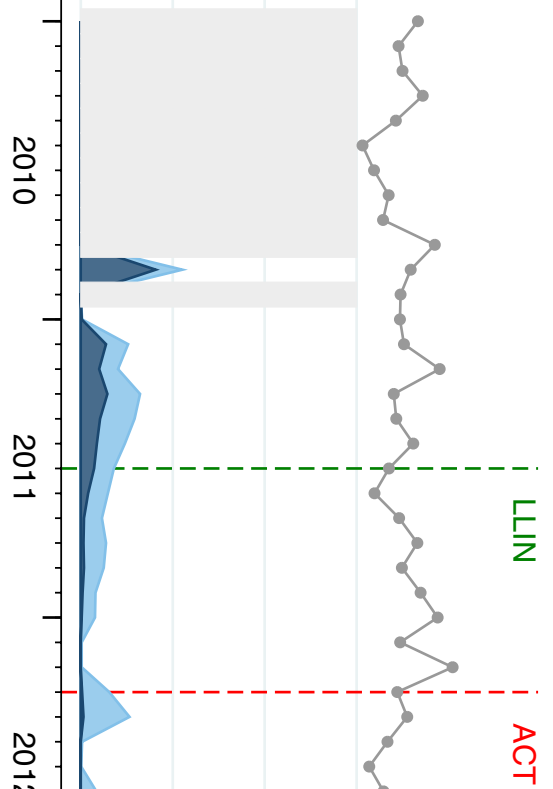

츨 을.

Fig. 3 Malaria cases in Highlands Region (Karimui) site. Left of each panel: monthly number of fever cases RDT negative (bright blue) and RDT positive (dark blue); cumulative monthly rainfall (grey line); timing of LLIN distribution and introduction of ACT (vertical dashed lines). Missing data is indicated by light grey shaded background. Right of each panel: annual RDT positivity (bar total) by species: P. falciparum (orange), P. vivax (green), mixed infections (yellow), no species data available (white)

to $187 / 1000$ in Lemakot in the peak year 2012. Incidence rates were highest in East Cape and Lemakot, except in 2014, when Sausi exhibited significantly higher incidence than the other sites. Severe malaria incidence ranged from 0.4/1000 in Karimui in 2014 to 28/1000 in Lemakot in 2011. In general, severe malaria incidence was highest in 2011 and lowest in 2014, except in Sausi, where a 2.6-fold increase was observed after 2013 (Table 2). The annual proportion of malaria cases being severe malaria ranged from 4\% in East Cape in 2013 to 67\% in Karimui in 2014. In Balimo and Arawa all severe malaria cases were attributed to $P$. falciparum. The greatest proportion of severe malaria with $P$. vivax (39\%) was observed in Karimui in 2011 but by 2014 all cases were P. falciparum (Additional file 5). Since the number of severe malaria cases is very low in Karimui some of the variations might be attributed to chance fluctuations.

The effect of the LLIN distribution on age-specific malaria incidence was assessed in the four sites with available age-specific population data. Malaria incidence was reduced with each LLIN distribution round in East Cape, Karimui and Lemakot. The greatest decrease was observed in the age groups 0-4 years and 5-9 years (Fig. 6). Incidence in Sausi initially decreased but increased again after the third distribution. When disaggregated by age group and gender, females in some sites and age groups appeared to have a higher incidence of malaria, e.g., in Lemakot (age group 15-19) and Sausi (age group 30-39), and differences in incidence rates between distribution rounds did not always affect males and females equally (Additional file 6).

Self-reported LLIN use increased in general with each distribution round and then gradually decreased over the subsequent years. Net use was highest in Sausi (90$100 \%)$, Balimo (95-100\%) and Dreikikir (77-86\%) and lowest in the two Islands sites of Arawa (21-69\%) and Lemakot (41-48\%), confirming data of the 2010/2011 national malaria indicators survey (Additional file 7) [18]. The treatment of malaria patients with ACT was consistently high ( $>80 \%$ each year) after the introduction of the drug in Balimo, East Cape, Dreikikir, Sausi, and Lemakot. The previous treatment combination of amodiaquine or 

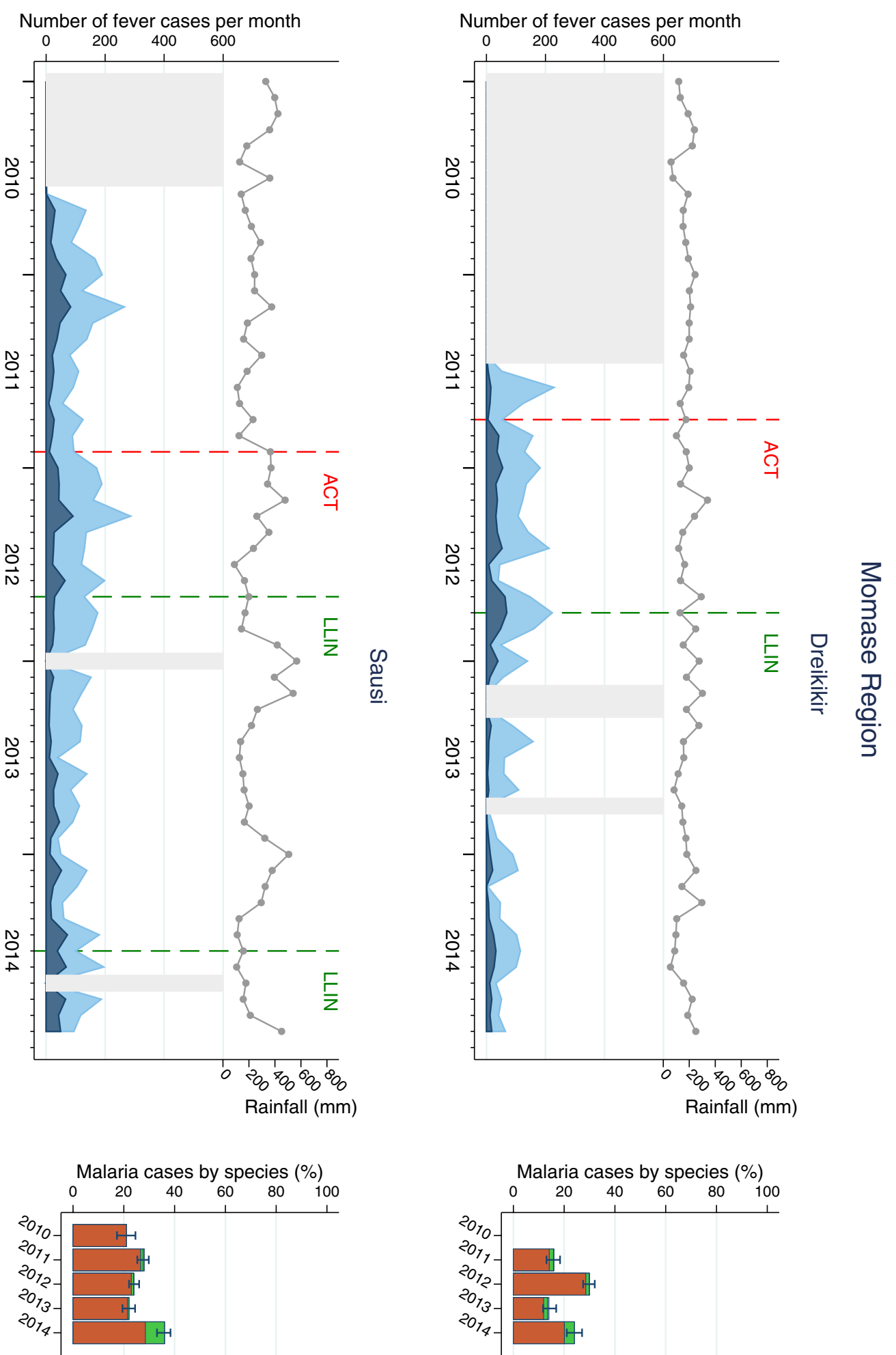

Fig. 4 Malaria cases in Momase Region (Dreikikir and Sausi) sites. Left of each panel: monthly number of fever cases RDT negative (bright blue) and RDT positive (dark blue); cumulative monthly rainfall (grey line); timing of LLIN distribution and introduction of ACT (vertical dashed lines). Missing data is indicated by light grey shaded background. Right of each panel: annual RDT positivity (bar total) by species: P. falciparum (orange), P. vivax (green), mixed infections (yellow), no species data available (white) 

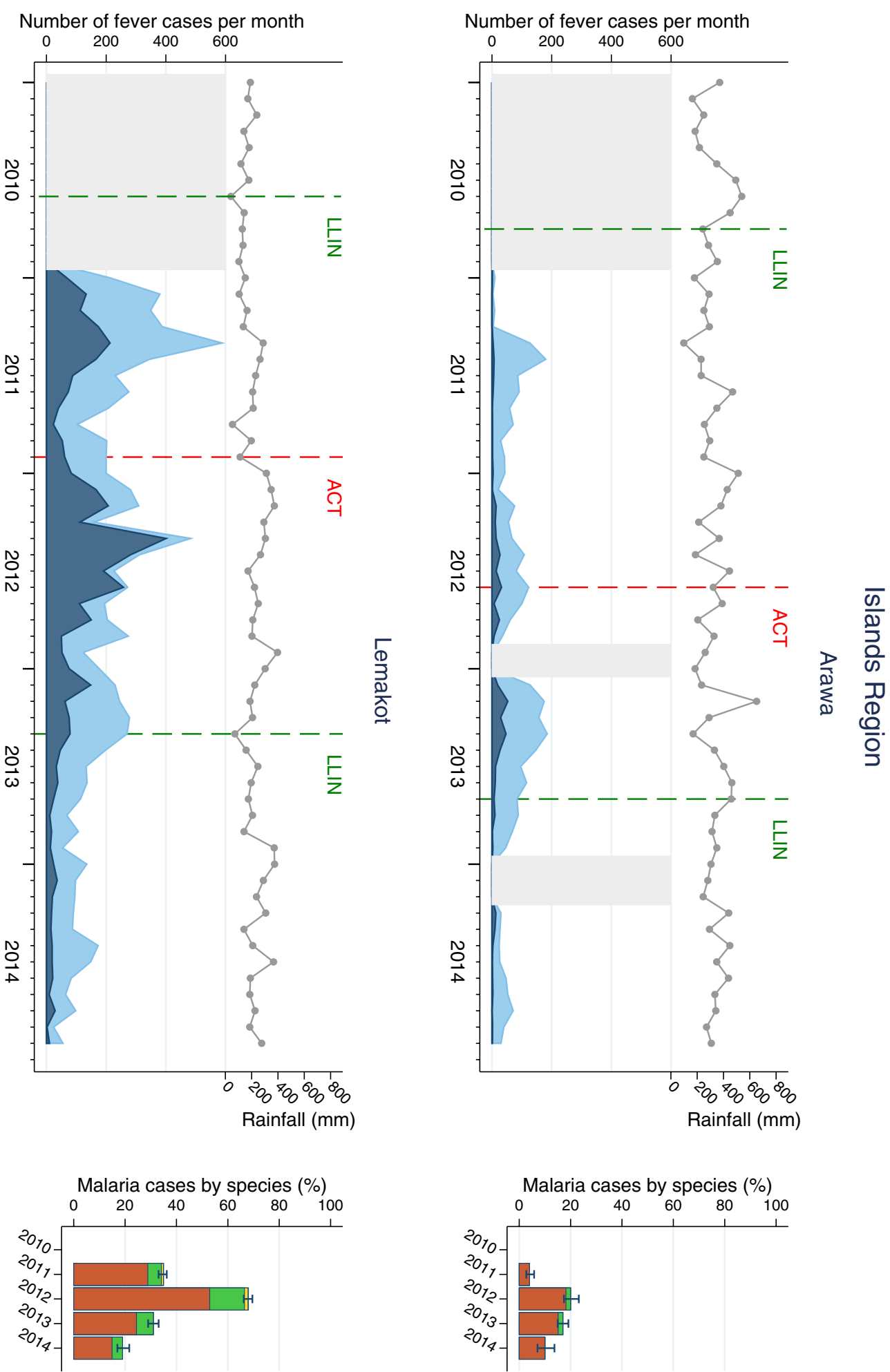

Fig. 5 Malaria cases in Islands Region (Arawa and Lemakot) sites. Left of each panel: monthly number of fever cases RDT negative (bright blue) and RDT positive (dark blue); cumulative monthly rainfall (grey line); timing of LLIN distribution and introduction of ACT (vertical dashed lines). Missing data is indicated by light grey shaded background. Right of each panel: annual RDT positivity (bar total) by species: P. falciparum (orange), P. vivax (green), mixed infections (yellow), no species data available (white) 
Table 2 Annual incidence of malaria and 'severe malaria' per 1000 population in four sentinel health facilities

\begin{tabular}{|c|c|c|c|c|c|c|c|c|c|c|}
\hline \multirow[t]{2}{*}{ Health facility } & \multicolumn{2}{|c|}{2010} & \multicolumn{2}{|c|}{2011} & \multicolumn{2}{|c|}{2012} & \multicolumn{2}{|c|}{2013} & \multicolumn{2}{|c|}{2014} \\
\hline & $\mathbf{N}$ & $95 \% \mathrm{Cl}$ & $\mathrm{N}$ & $95 \% \mathrm{Cl}$ & $\mathrm{N}$ & $95 \% \mathrm{Cl}$ & $\mathrm{N}$ & $95 \% \mathrm{Cl}$ & $\mathrm{N}$ & $95 \% \mathrm{Cl}$ \\
\hline \multicolumn{11}{|c|}{ Malaria incidence } \\
\hline East Cape & 115 & $(107,124)$ & 117 & $(109,125)$ & 179 & $(170,189)$ & 141 & $(133,150)$ & 47 & $(42,52)$ \\
\hline Karimui & 19 & $(16,22)$ & 34 & $(31,38)$ & 6 & $(4,8)$ & 6 & $(5,8)$ & 1 & $(0.2,1)$ \\
\hline Sausi & 20 & $(17,24)$ & 79 & $(72,86)$ & 79 & $(72,87)$ & 43 & $(38,48)$ & 79 & $(72,86)$ \\
\hline Lemakot & - & - & 113 & $(107,119)$ & 187 & $(180,194)$ & 55 & $(51,59)$ & 19 & $(17,22)$ \\
\hline \multicolumn{11}{|c|}{ 'Severe malaria' incidence } \\
\hline East Cape & 7 & $(5,9)$ & 24 & $(20,28)$ & 10 & $(8,13)$ & 6 & $(4,8)$ & 3 & $(2,5)$ \\
\hline Karimui & 2 & $(1,4)$ & 14 & $(12,17)$ & 3 & $(2,4)$ & 2 & $(1,3)$ & 0.4 & $(0.1,1)$ \\
\hline Sausi & 1 & $(1,3)$ & 18 & $(15,22)$ & 13 & $(10,16)$ & 8 & $(6,10)$ & 21 & $(17,25)$ \\
\hline Lemakot & - & - & 28 & $(25,31)$ & 27 & $(24,30)$ & 6 & $(5,8)$ & 4 & $(3,5)$ \\
\hline
\end{tabular}

Only sites with available census denominator data were included

Cl confidence interval

chloroquine plus sulfadoxine-pyrimethamine (SP) was phased out over the same period. The opposite trend was observed in Karimui, where ACT was gradually substituted by the previous treatment regimen 1 year after its introduction and in Arawa, where in 2014, most patients were treated neither with the old, nor with the new regimen (Additional file 8). Annually, less than $1.3 \%$ of negative cases were treated with ACT in all SHFs. Information on the use of primaquine is available in the Additional file 9.

Due to significant heterogeneity in the estimated effects of LLIN distribution rounds on the number of malaria cases between sites $(\mathrm{p}<0.001$, interaction test), the effects of interventions were estimated for each SHF individually and adjusted for El Niño/La Niña years. In general, subsequent distribution of LLINs led to cumulative reductions in the number of malaria cases (Table 3). The greatest reductions were in settings where the number of cases was the lowest (Balimo, Karimui, Arawa) rather than in places with high net use but high case load. In Sausi, where an earlier study had suggested significant impact of the first LLIN distribution [9], the second distribution reduced the number of cases by $57 \%$ (95\% CI $11-79 \%)$ but a two-fold increase was observed after the third distribution.

The change of treatment from amodiaquine or chloroquine plus SP to ACT did not appear to significantly affect the number of malaria cases except in Drekikir and Lemakot where an increase was observed.

\section{Discussion}

Malaria surveillance in SHFs revealed varying trends in the number of malaria cases and the magnitude of their association with control interventions between 2010 and 2014. In general, reductions in the number of malaria cases were observed with each of three rounds of household-level LLIN distribution while no substantial reductions followed the change of treatment to ACT. The number of malaria cases was found to increase in one site after the third distribution round. The findings disclose a substantial sub-national heterogeneity in the epidemiology and control of malaria in PNG.

After the first large-scale LLIN distribution in PNG, data from six sentinel surveillance sites indicated a drop in the average monthly malaria incidence rate from $13 / 1000$ population to $2 / 1000$ (incidence rate ratio $=0.12$; 95\% CI 0.09-0.17) and reductions in prevalence and transmission confirming significant short-term effect of LLIN in the absence of ACT [9]. Previous modelling studies suggested that the effect of LLIN may fade over time as acquired immunity in the population is reduced, particularly in areas with a high pre-intervention entomological inoculation rate [19]. The situation observed in Dreikikir and Sausi is consistent with this prediction. On the other hand, considering LLIN coverage was consistently high (self-reported use $90-100 \%$ in Sausi, $77-89 \%$ in Dreikikir, Additional file 5) [9], other factors such as aging of nets may fuel ongoing transmission. In the absence of insecticide resistance, early and outdoor biting of Anopheles mosquitoes has been identified as a threat to the effectiveness of LLINs. Entomological studies in Sausi have described a shift in mosquito biting to earlier hours following the first LLIN distribution (the peak exposure time to infectious bites shifted from later than 9 p.m. in 2008 to between 6 and 7 p.m. in 2011) resulting in decreased protection against mosquito bites $[10,20]$.

Gender differences, or anomalies in the age-specific incidence rates, (e.g., higher incidence rates in females age 15-19 in Lemakot; Additional file 6) might suggest 


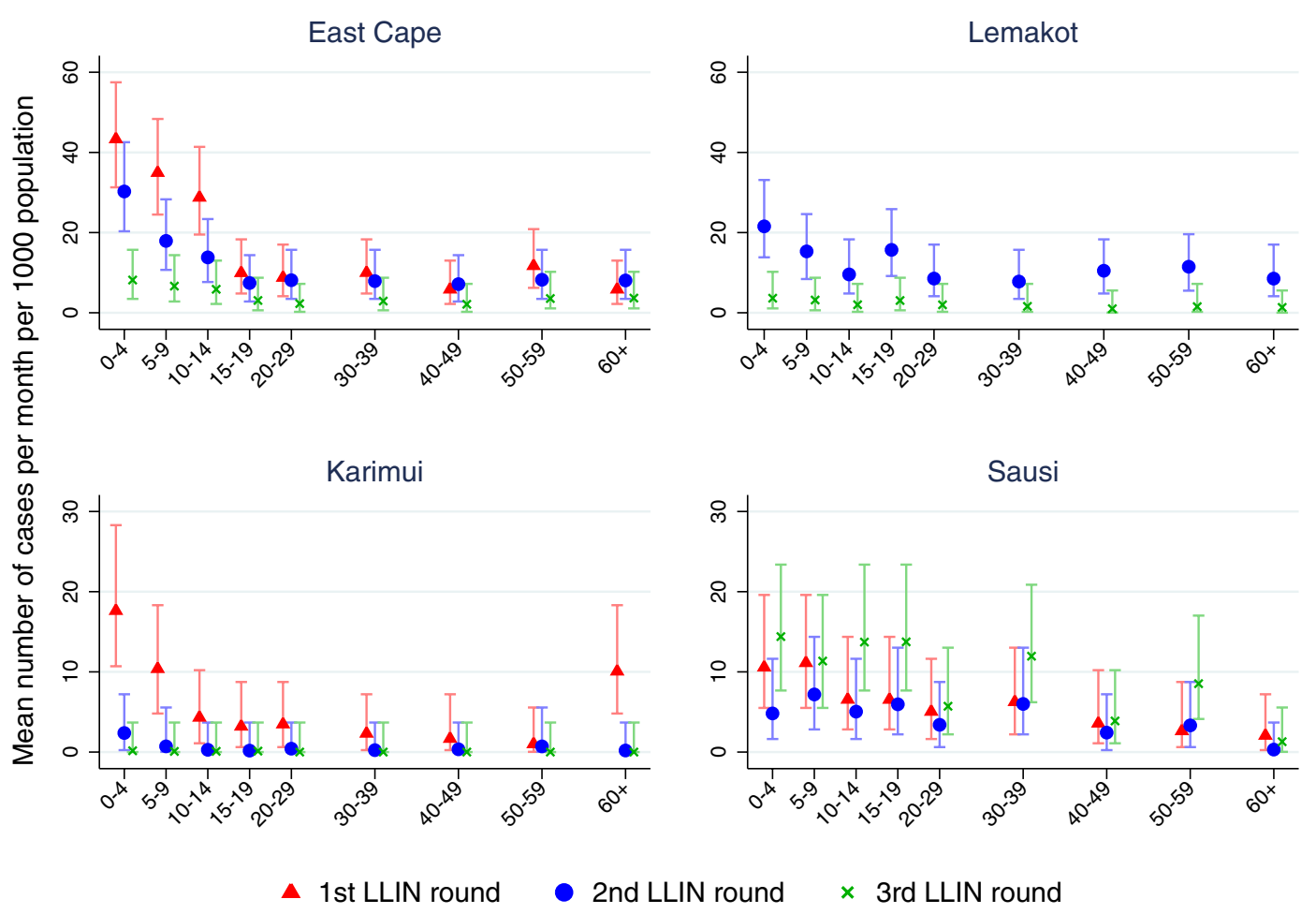

Fig. 6 Malaria incidence rate by age group after each LLIN distribution round in four sites. LLIN long-lasting insecticide-treated bed net

Table 3 Estimated effects of each round of LLIN distribution and ACT introduction on the number of malaria cases by sentinel health facility

\begin{tabular}{|c|c|c|c|c|c|c|}
\hline \multirow[t]{2}{*}{ Health facility } & \multicolumn{2}{|c|}{$\begin{array}{l}\text { 2nd vs. 1st } \\
\text { LLIN distribution }\end{array}$} & \multicolumn{2}{|c|}{$\begin{array}{l}\text { 3rd vs. 2nd } \\
\text { LLIN distribution }\end{array}$} & \multicolumn{2}{|c|}{ Introduction of ACT } \\
\hline & IRR & $95 \% \mathrm{Cl}$ & IRR & $95 \% \mathrm{Cl}$ & IRR & $95 \% \mathrm{Cl}$ \\
\hline Balimo & - & - & $1.32 \mathrm{E}-09$ & $(0.00,-)$ & 1.21 & $(0.47,3.14)$ \\
\hline East Cape & 0.53 & $(0.20,1.41)$ & 0.34 & $(0.18,0.64)$ & 1.50 & $(0.79,2.85)$ \\
\hline Karimui & 0.19 & $(0.06,0.58)$ & 0.12 & $(0.03,0.43)$ & 0.95 & $(0.32,2.80)$ \\
\hline Dreikikir & 1.15 & $(0.54,2.46)$ & - & - & 3.95 & $(1.89,8.25)$ \\
\hline Sausi & 0.43 & $(0.21,0.89)$ & 2.08 & $(1.16,3.72)$ & 1.28 & $(0.76,2.16)$ \\
\hline Arawa & - & - & 0.15 & $(0.06,0.36)$ & 1.79 & $(0.57,5.64)$ \\
\hline Lemakot & - & - & 0.26 & $(0.14,0.50)$ & 1.73 & $(1.09,2.75)$ \\
\hline
\end{tabular}

All estimates were adjusted for La Niña or El Niño year

IRR incidence rate ratio, $\mathrm{Cl}$ confidence interval

gender-specific risk. In Lemakot, the substantial increase in malaria cases in 2012 was disproportionately due to cases in teenage girls, suggesting a local outbreak. Age or gender-specific behaviour (e.g., evening activities, division of household chores) or other social or cultural determinants including location and quality of houses may result in different levels of exposure. Such factors have been well investigated in settings in which most of the transmission is limited to specific population groups (e.g., in Southeast Asia [21-23]). In highly diverse settings such as PNG, one challenge will be to identify risk factors that disproportionately affect particular population groups, and to translate such knowledge into targeted control action. A mixed methods approach that captures behavioural patterns alongside prevalence and incidence data, linked with entomological investigations in settings with ongoing transmission, will be an important first step. 
Most of the evidence of the impact of insecticidetreated nets originates from African settings and is limited to the effect on P. falciparum [24]. While multiple studies demonstrated the effect of LLIN programmes on P. falciparum incidence (e.g. $[25,26])$, evidence from settings with several Plasmodium species is scarce. Although it has been suggested that the impact of vector control on $P$. vivax may be delayed due to the parasite's biology, this study only found short-term transient increases in the proportion of $P$. vivax by light microscopy, suggesting that at intermediate to high transmission, both species are affected by vector control and both species may resurge. A modelling study found that in such areas LLINs alone could not lead to interruption of $P$. vivax transmission and additional tools are required to accelerate to elimination [27]. Considering the abundance of low level parasitaemia, particularly in $P$. vivax infections as transmission is reduced, more sensitive diagnostic tools may need to be applied to monitor progress and species composition [28].

A number of field and modelling studies have shown a reduction in malaria cases and/or transmission after the introduction of ACT alone and in combination with LLINs [29-34]. In this study, the change in first-line treatment from amodiaquine or chloroquine plus SP to ACT did not lead to a decrease in the number of cases. Neither did it result in an increase in the proportion of $P$. vivax cases despite the higher susceptibility of $P$. falciparum to artemether-lumefantrine [35] and the low consistent use of primaquine as radical cure of $P$. vivax. In general, the previous treatment was used widely (though not always strictly according to guidelines) before the introduction of ACT (Additional file 7) and the regimen had retained approximately 82\% efficacy (chloroquine plus SP in 20052007 [35]) limiting the increase in efficacy after ACT rollout to $13 \%$. Additionally, while an efficacious drug can improve clinical outcomes [36] a community-wide effect on transmission (and hence incidence) is, among other factors, a function of treatment seeking and prevalence of asymptomatic and sub-microscopic infections. Individuals with asymptomatic infections fuel ongoing transmission and do not seek treatment [8, 37, 38]. In PNG, only $43 \%$ of fever cases were found to have attended a health facility (2013/14) [39], thus the increase in efficacy might have been insufficient to translate into reduced transmission and incidence, as already demonstrated in an African high-transmission setting [40]. In the two sites in which an increase in the number of malaria cases was observed following the introduction of ACT, overall facility attendance did not suggest an availability effect resulting from the introduction of free intervention, as documented elsewhere $[41,42]$. A recent study in PNG even suggests that the shift to test-based ACT treatment may have negatively impacted treatment seeking and patient satisfaction, possibly related to low perceived quality of care provided to patients with non-malarial illness [43]. Differences in the length of post-intervention periods used for the regression model may have affected the reliability of estimates for Dreikikir as the period preceding ACT introduction was only 3 months (Additional file 2), most likely not enough to gain reliable estimates for both interventions.

Different surveillance starting points and lack of preLLIN data were limitations to this study but data from previous surveillance activities and national prevalence surveys provide supporting evidence of the short-term effect of LLINs $[4,8,9]$. Fluctuations in treatment seeking or facility attendance may have influenced incidence estimates to a certain degree, but data from repeat national surveys suggests that the proportion of fever patients attending a formal health facility has remained largely unchanged since the first assessment in 2008/09 [44].

Despite previous validation and use in other settings $[14,45]$, none of the available site-specific satellite weather variable (EVI: MODIS products MOD13Q1 and MOD13A3; and rainfall: TRMM product 3B43) could explain variations in malaria incidence over time which supports historical descriptions of an intricate and complex environment driving malaria epidemiology across in PNG $[2,5,8,46,47]$. Particularly in an environment with high overall rainfall, weather variables may not be a good single predictor of malaria incidence. In contrast the El Niño/La Niña phenomena appeared to be a useful and more stable environmental predictor since it affects larger areas for a longer period of time than site-specific weather data.

Differences in pre-intervention malaria transmission and in the impact of interventions between sites are a function of the diverse social and ecological settings which lead to differences in vector abundance, vector behaviour and human-vector interaction. Multi-disciplinary studies on a smaller scale are required to broaden the understanding of malaria transmission dynamics on a sub-national level and identify regional factors driving the observed heterogeneity. Insights from such investigations should be translated into response strategies that take into consideration sub-national heterogeneity in the drivers of ongoing malaria transmission. A robust surveillance system reporting case incidence should be supported by monitoring of entomological and immunological parameters to explain differences in the impact of interventions. 


\section{Conclusions}

Subsequent household level distributions of LLINs had a cumulative effect on reducing the number of malaria cases in the SHFs but the magnitude of the association varied between sites and over time. Changing treatment to ACT had no apparent effect. Malaria programmes covering diverse transmission settings such as PNG must consider local heterogeneity when choosing interventions and ensure continuous monitoring of trends.

\section{Supplementary information}

Supplementary information accompanies this paper at https://doi. org/10.1186/s12936-019-2993-6.

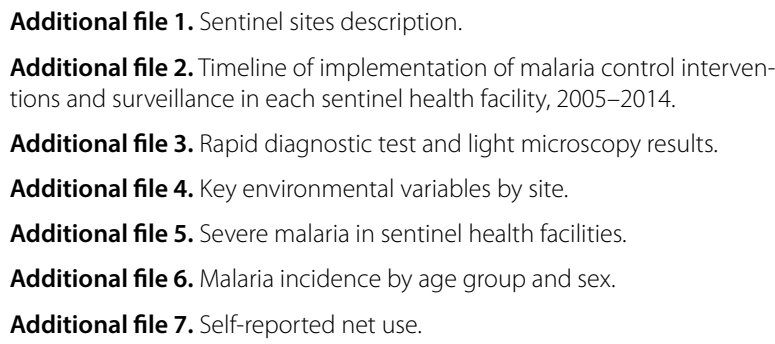

Additional file 3. Rapid diagnostic test and light microscopy results.

Additional file 4. Key environmental variables by site.

Additional file 5. Severe malaria in sentinel health facilities.

Additional file 6. Malaria incidence by age group and sex.

Additional file 7. Self-reported net use.

Additional file 8. Percentage of malaria cases treated with the previous first line treatment or partial treatment (mono-therapy), and with artemisinin-based combination therapy.

Additional file 9. Percentage of malaria cases treated with primaquine (for different RDT results), and with artemisinin-based combination therapy.

\section{Abbreviations}

ACT: artemisinin-based combination therapy; Cl: confidence interval; DDT: dichlorodiphenyltrichloroethane; EOS: Earth Observing System; EVI: Enhanced Vegetation Index; GES DISC: Goddard Earth Sciences Data and Information Services Center; Hb: haemoglobin; IRR: incidence rate ratio; LLIN: long-lasting insecticidal net; NASA: National Aeronautics and Space Administration; NMCP: National malaria control programme; PNG: Papua New Guinea; PNGIMR: Papua New Guinea Institute of Medical Research; RDT: rapid diagnostic test; SHF: sentinel health facilities; SP: sulfadoxine-pyrimethamine; TRMM: Tropical Rainfall Measuring Mission.

\section{Acknowledgements}

We thank all patients and communities who agreed to participate in this study. We are grateful to the study nurses who collected data and samples at the sentinel health facilities (Mrs. Naeobo Oren in East Cape, Mrs. Bridgette Kamuna in Balimo, Mr. Paul Basanu in Karimui, Ms. Rhona Sao in Sausi, Mrs. Brenda Sam in Dreikikir, Mrs. Lia Pitan in Lemakot and Mrs. Sandra Mangina in Arawa), and to the authorities and organizations hosting them. We thank the PNGIMR census field teams, the data managers, data entry staff and microscopists and acknowledge the support of the National Department of Health through Mr. Leo Makita and his team. Kees De Hoogh kindly provided support to explore remote-sensing databases for the environmental variables used in the study.

\section{Authors' contributions}

MWH, IM, PMS and JP conceived of the study. SM, MWH and JP established and supervised data collection systems. $L L$ and LJR were in charge of malaria diagnosis by light microscopy. DRR analysed the data with support from AR and drafted the manuscript with major inputs from MWH, AR and JP. All authors read and approved the final manuscript

\section{Funding}

Funding for data collection was provided through a Global Fund to Fight AIDS, Tuberculosis and Malaria Round 8 malaria grant. DRR was supported by the Forlen Stiftung, Basel, and the R. Geigy Foundation, Basel, Switzerland.

\section{Availability of data and materials}

The datasets used and/or analysed during the current study are available from the corresponding author on reasonable request.

\section{Ethics approval and consent to participate}

Fever patients were asked for verbal consent prior to sample collection. For children below 16 years of age consent was obtained from the parent or caregiver. Ethical clearance was granted by the Institutional Review Board of the PNGIMR and the PNG Medical Research Advisory Committee (MRAC No. 10.12).

\section{Consent for publication}

Not applicable.

\section{Competing interests}

The authors declare that they have no competing interests.

\section{Author details}

1 Swiss Tropical and Public Health Institute, Basel, Switzerland. ${ }^{2}$ University of Basel, Basel, Switzerland. ${ }^{3}$ Papua New Guinea Institute of Medical Research, Goroka and Madang, Papua New Guinea. ${ }^{4}$ Walter and Eliza Hall Institute of Medical Research, Melbourne, Australia. ${ }^{5}$ Burnet Institute, Melbourne, Australia. ${ }^{6}$ Institut Pasteur, Paris, France. ${ }^{7}$ Liverpool School of Tropical Medicine, Liverpool, UK.

Received: 30 April 2019 Accepted: 4 November 2019

Published online: 12 November 2019

\section{References}

1. Ewers WH. Robert Koch, his work in New Guinea, and his contribution to malariology. PNG Med J. 1972;15:7-24.

2. Attenborough RD, Alpers MP. Human biology in Papua New Guinea: the small cosmos. Oxford: Oxford University Press; 1992.

3. Betuela I, Maraga S, Hetzel MW, Tandrapah T, Sie A, Yala S, et al. Epidemiology of malaria in the Papua New Guinean highlands. Trop Med Int Health. 2012;17:1181-91.

4. Hetzel MW, Morris H, Tarongka N, Barnadas C, Pulford J, Makita L, et al. Prevalence of malaria across Papua New Guinea after initial roll-out of insecticide-treated mosquito nets. Trop Med Int Health. 2015;20:1745-55.

5. Mueller I, Bockarie MJ, Alpers MP, Smith TA. The epidemiology of malaria in Papua New Guinea. Trends Parasitol. 2003;19:253-9.

6. Parkinson AD. Malaria in Papua New Guinea 1973. PNG Med J. $1974 ; 17: 8-16$

7. Hetzel MW, Pulford J, Maraga S, Barnadas C, Reimer LJ, Tavul L, et al. Evaluation of the Global Fund-supported National Malaria Control Program in Papua New Guinea, 2009-2014. PNG Med J. 2014;57:7-29.

8. Hetzel MW, Pulford J, Ura Y, Jamea-Maiasa S, Tandrapah T, Tarongka $\mathrm{N}$, et al. Insecticide-treated nets and malaria prevalence, Papua New Guinea, 2008-2014. Bull World Health Organ. 2017;95:695-705B.

9. Hetzel MW, Reimer LJ, Gideon G, Koimbu G, Barnadas C, Makita L, et al. Changes in malaria burden and transmission in sentinel sites after the roll-out of long-lasting insecticidal nets in Papua New Guinea. Parasites Vectors. 2016;9:340.

10. Reimer LJ, Thomsen EK, Koimbu G, Keven JB, Mueller I, Siba PM, et al. Malaria transmission dynamics surrounding the first nationwide long-lasting insecticidal net distribution in Papua New Guinea. Malar J. 2016;15:25.

11. Cattani JA, Moir JS, Gibson FD, Ginny M, Paino J, Davidson W, et al. Smallarea variations in the epidemiology of malaria in Madang Province. PNG Med J. 1986;29:11-7. 
12. National Statistical Office. 2011 national population and housing census of Papua New Guinea - final figures. Port Moresby: National Statistical Office; 2013.

13. Precipitation Processing System Tropical Rainforest Measuring Mission. File Specification for TRMM Products. 2017. p. 0-329.

14. Midekisa A, Senay G, Henebry GM, Semuniguse P, Wimberly MC. Remote sensing-based time series models for malaria early warning in the highlands of Ethiopia. Malar J. 2012;11:165.

15. Dinku T, Ceccato P, Grover-Kopec E, Lemma M, Connor SJ, Ropelewski CF. Validation of satellite rainfall products over East Africa's complex topography. Int J Remote Sensing. 2007;28:1503-26.

16. Didan K, Barreto Munoz A, Solano R, Huete A. MODIS vegetation index user's guide (MOD13 Series). Arizona: Vegetation index and Phenology Lab; 2015.

17. Carlowicz M, Schollaert Uz S. El Niño: pacific wind and current changes bring warm, wild weather. NASA Earth Observatory; 2017.

18. Hetzel MW, Choudhury AAK, Pulford J, Ura Y, Whittaker M, Siba PM, et al. Progress in mosquito net coverage in Papua New Guinea. Malar J. 2014;13:242.

19. Briët OJT, Penny MA. Repeated mass distributions and continuous distribution of long-lasting insecticidal nets: modelling sustainability of health benefits from mosquito nets, depending on case management. Malar J. 2013;12:401.

20. Thomsen EK, Koimbu G, Pulford J, Jamea-Maiasa S, Ura Y, Keven $\mathrm{JB}$, et al. Mosquito behavior change after distribution of bednets results in decreased protection against malaria exposure. J Infect Dis. 2017:215:790-7.

21. Cui L, Yan G, Sattabongkot J, Cao Y, Chen B, Chen X, et al. Malaria in the Greater Mekong Subregion: heterogeneity and complexity. Acta Trop. 2012;121:227-39.

22. Thanh PV, Van Hong N, Van Van N, Van Malderen C, Obsomer V, Rosanas-Urgell A, et al. Epidemiology of forest malaria in Central vietnam: the hidden parasite reservoir. Malar J. 2015;14:86.

23. Gryseels C, Durnez L, Gerrets R, Uk S, Suon S, Set S, et al. Re-imagining malaria: heterogeneity of human and mosquito behaviour in relation to residual malaria transmission in Cambodia. Malar J. 2015;14:165.

24. Pryce J, Richardson M, Lengeler C. Insecticide-treated nets for preventing malaria. Cochrane Database Syst Rev. 2018;11:CD000363.

25. Aregawi MW, Lynch M, Bekele W, Kebede H, Jima D, Taffese HS, et al. Time series analysis of trends in malaria cases and deaths at hospitals and the effect of antimalarial interventions, 2001-2011, Ethiopia. PLoS ONE. 2014;9:e106359.

26. Aregawi M, Malm KL, Wahjib M, Kofi O, Allotey NK, Yaw PN, et al. Effect of anti-malarial interventions on trends of malaria cases, hospital admissions and deaths, 2005-2015, Ghana. Malar J. 2017;16:177

27. White MT, Walker P, Karl S, Hetzel MW, Freeman T, Waltmann A, et al. Mathematical modelling of the impact of expanding levels of malaria control interventions on Plasmodium vivax. Nat Commun. 2018;9:1-10.

28. Hofmann NE, Gruenberg M, Nate E, Ura A, Rodriguez-Rodriguez D, Salib M, et al. Assessment of ultra-sensitive malaria diagnosis versus standard molecular diagnostics for malaria elimination: an in-depth molecular community cross-sectional study. Lancet Infect Dis. 2018:18:1108-16.

29. Bretscher MT, Griffin JT, Ghani AC, Okell LC. Modelling the benefits of long-acting or transmission-blocking drugs for reducing Plasmodium falciparum transmission by case management or by mass treatment. Malar J. 2017;16:341.

30. Shah NK, Tyagi P, Sharma SK. The impact of artemisinin combination therapy and long-lasting insecticidal nets on forest malaria incidence in tribal villages of India, 2006-2011. PLoS ONE. 2013;8:e56740.

31. Okell LC, Drakeley CJ, Bousema T, Whitty CJM, Ghani AC. Modelling the impact of artemisinin combination therapy and long-acting treatments on malaria transmission intensity. PLoS Med. 2008;5:e226.

32. Bhattarai A, Ali AS, Kachur SP, Mårtensson A, Abbas AK, Khatib R, et al Impact of artemisinin-based combination therapy and insecticidetreated nets on malaria burden in Zanzibar. PLoS Med. 2007:4:e309.

33. Barnes Kl, Durrheim DN, Little F, Jackson A, Mehta U, Allen E, et al. Effect of artemether-lumefantrine policy and improved vector control on malaria burden in KwaZulu-Natal, South Africa. PLoS Med. 2005;2:e330.

34. Nosten F, van Vugt M, Price RN, Luxemburger C, Thway KL, McGready $R$, et al. Effects of artesunate-mefloquine combination on incidence of
Plasmodium falciparum malaria and mefloquine resistance in western Thailand: a prospective study. Lancet. 2000;356:297-302.

35. Karunajeewa HA, Mueller I, Senn M, Lin E, Law I, Gomorrai PS, et al. A trial of combination antimalarial therapies in children from Papua New Guinea. N Engl J Med. 2008;359:2545-57.

36. Bhatt S, Weiss DJ, Cameron E, Bisanzio D, Mappin B, Dalrymple U, et al. The effect of malaria control on Plasmodium falciparum in Africa between 2000 and 2015. Nature. 2015;526:207-11.

37. Robinson LJ, Wampfler R, Betuela I, Karl S, White MT, Li Wai Suen CSN, et al. Strategies for understanding and reducing the Plasmodium vivax and Plasmodium ovale hypnozoite reservoir in Papua New Guinean children: a randomised placebo-controlled trial and mathematical model. PLoS Med. 2015;12:e1001891.

38. Bousema T, Okell L, Felger I, Drakeley C. Asymptomatic malaria infections: detectability, transmissibility and public health relevance. Nat Rev Microbiol. 2014;12:833-40.

39. Hetzel MW, Pulford J, Gouda H, Hodge A, Siba PM, Mueller I. The Papua New Guinea National Malaria Control Program: primary outcome and impact indicators, 2009-2014. Goroka: PNG Institute of Medical Research; 2014.

40. Huho BJ, Killeen GF, Ferguson HM, Tami A, Lengeler C, Charlwood JD, et al. Artemisinin-based combination therapy does not measurably reduce human infectiousness to vectors in a setting of intense malaria transmission. Malar J. 2012;11:118.

41. Ansah EK, Narh-Bana S, Asiamah S, Dzordzordzi V, Biantey K, Dickson K, et al. Effect of removing direct payment for health care on utilisation and health outcomes in Ghanaian children: a randomised controlled trial. PLoS Med. 2009;6:e1000007

42. Heinmüller R, Dembélé YA, Jouquet G, Haddad S, Ridde V. Free healthcare provision with an NGO or by the Malian government. Field Actions Science Reports. 2013;8:1731.

43. Pulford J, Saweri OPM, Jeffery C, Siba PM, Mueller I, Hetzel MW. Does test-based prescription of evidence-based treatment for malaria improve treatment seeking and satisfaction? Findings of repeated cross-sectional surveys in Papua New Guinea. BMJ Global Health. 2018;3:e000915.

44. Hetzel MW, Saweri OPM, Kuadima JJ, Smith I, Tandrapah A, Ura Y, Tandrapah A, et al. Papua New Guinea Malaria Indicator Survey 20162017: malaria prevention, infection, and treatment. Goroka: PNG Institute of Medical Research; 2018.

45. Ceccato $P$, Connor SJ, Jeanne I, Thomson MC. Application of geographical information systems and remote sensing technologies for assessing and monitoring malaria risk. Parassitologia. 2005:47:81-96.

46. Mueller I, Tulloch J, Marfurt J, Hide R, Reeder JC. Malaria control in Papua New Guinea results in complex epidemiological changes. PNG Med J. 2005:48:151-7

47. Radford AJ, Van Leeuwen H, Christian SH. Social aspects in the changing epidemiology of malaria in the highlands of New Guinea. Ann Trop Med Parasitol. 1976;70:11-23.

\section{Publisher's Note}

Springer Nature remains neutral with regard to jurisdictional claims in published maps and institutional affiliations.

Ready to submit your research? Choose BMC and benefit from:

- fast, convenient online submission

- thorough peer review by experienced researchers in your field

- rapid publication on acceptance

- support for research data, including large and complex data types

- gold Open Access which fosters wider collaboration and increased citations

- maximum visibility for your research: over 100M website views per year

At BMC, research is always in progress.

Learn more biomedcentral.com/submissions 